\title{
Posterior Fossa Syndrome
}

National Cancer Institute

\section{Source}

National Cancer Institute. Posterior Fossa Syndrome. NCI Thesaurus. Code C116378.

A postoperative syndrome, usually presenting after midline posterior fossa tumor resection, that involves a variety of signs and symptoms including aphasia, mutism or speech disturbances, dysphagia, mobility problems, cranial nerve palsies and emotional instability. 